\title{
Liquid Phase Oxidation of Acetophenone over Rice Husk Silica Vanadium Catalyst
}

\author{
Farook ADAM*, Thiam-Seng CHEW, Jeyashelly ANDAS \\ School of Chemical Sciences, Universiti Sains Malaysia, Penang 11800, Malaysia
}

\begin{abstract}
Rice husk silica catalyst loaded with $10 \mathrm{wt} \%$ vanadium was synthesized from agricultural biomass via a sol-gel synthetic route at $\mathrm{pH}=9$. The catalyst was characterized by different physico-chemical methods. The FTIR spectra showed the formation of $\mathrm{Si}-\mathrm{O}-\mathrm{V}$ and $\mathrm{V}=\mathrm{O}$ stretching bands. The presence of vanadium was confirmed by EDX elemental analysis. RH-10V possessed a high specific surface area of $276 \mathrm{~m}^{2} / \mathrm{g}$ and pore volume of $0.83 \mathrm{ml} / \mathrm{g}$. The prepared catalyst possessed a narrow pore size distribution centered around $7.9 \mathrm{~nm}$. The catalytic performance of RH- $10 \mathrm{~V}$ was tested in the oxidation of acetophenone at $70{ }^{\circ} \mathrm{C}$. RH- $10 \mathrm{~V}$ was found to be an active catalyst in the oxidation of acetophenone, producing 36.28\% conversion efficiency. The products identified were benzoic acid, 2-hydroxyacetophenone, phenol, acetic acid, and 3-hydroxyacetophenone.
\end{abstract}

Key words: vanadium; rice husk silica; oxidation; acetophenone; sol-gel technique

CLC number: O643 Document code: A

Received 27 September 2011. Accepted 31 December 2011.

*Corresponding author. Tel: +60-46533567; Fax:+60-46574854; E-mail: farook@usm.my,farook_dr@yahoo.com

This work was supported by the Malaysian Government (RU Grant 1001/PKIMIA/811092)

English edition available online at Elsevier ScienceDirect (http://www.sciencedirect.com/science/journal/18722067).

Acetophenone is an asymmetric ketone and its oxidation results in the formation of a mixture of products such as benzoic acid, benzoylformic acid, dibenzoylfunzan 2-oxide, benzyl alcohol, and phenol which have well-established industrial applications [1-5]. For example, benzoic acid is used as plasticizer, as a food preservative, in flavoring, in the synthesis of perfumes and antifungal agents [6]. Phenol is widely used to produce phenolic resin, solvents, dyes, and pharmaceuticals [7]. Nevertheless, only few researchers [1-5] have studied the oxidation of acetophenone. This is presumably due to acetophenone being a terminal ketone which has no hydrogen atoms on the carbinol carbon. Thus, oxidation of acetophenone can only be possible by breaking the $\alpha$ carbon-carbon bond [8].

Perkin [1] has reported the conversion of acetophenone to benzoic acid using sodium hypochlorite, which is the haloform reaction. However, from an environmental point of view, this method is not suitable for industrial use due to the formation of chloroform as a side product. Homogeneous catalysts such as 1,3-dinitrobenzene [2] and nitric acid [3] have been used to oxidize acetophenone. These homogeneous systems create problems in the separation process and catalyst recovery. Hence, Chumbahale and co-workers [4] have reported the vapor phase oxidation of acetophenone by $\mathrm{V}_{2} \mathrm{O}_{5}-\mathrm{MoO}_{3}$ catalyst resulting in the formation of maleic anhydride, benzyl alcohol, benzaldehyde, benzoic acid, and phthalic anhydride. They have also observed trace amounts of toluene, xylene, and phenol as by-products. Although this method manages to achieve high selectivity toward benzoic acid, it needs high temperature and long contact times which are limitations.

Vanadium shows a wide range of oxidation states $(+2$ to $+5)$ in aqueous solution. Moreover, heterogeneous vanadium catalysts have been used in various oxidation reactions [9-11]. To the best of our knowledge, the oxidation of acetophenone has not been carried out using catalyst synthesized from biomass rice husk (RH) silica. Since RH silica exhibits high surface area and high porosity [12], it is thought to be advantageous to prepare vanadium incorporated $\mathrm{RH}$ silica and evaluate the synthesized catalyst in the oxidation of acetophenone with aqueous hydrogen peroxide under mild conditions. This work describes the simplest, cost-effective, and green preparation of RH-vanadium catalyst for the liquid-phase oxidation of acetophenone.

\section{Experimental}

\subsection{Preparation of sodium silicate}

Preparation of sodium silicate was carried out by a modification of the technique reported by Adam and Chew [13]. The dried RH $(30.0 \mathrm{~g})$ was stirred in $600 \mathrm{ml}$ of $1.0 \mathrm{~mol} / \mathrm{L}$ $\mathrm{HNO}_{3}$ for $24 \mathrm{~h}$ to remove unwanted metal. The acid treated RH was filtered and washed with copious amount of dis- 
tilled water until it reached a constant $\mathrm{pH}$. It was oven dried at $383 \mathrm{~K}$ overnight. On cooling, the rice husk $\left(\mathrm{RH}-\mathrm{HNO}_{3}\right)$ was weighed. The $\mathrm{RH}-\mathrm{HNO}_{3}$ was stirred in $500 \mathrm{ml}$ of 1.0 $\mathrm{mol} / \mathrm{L} \mathrm{NaOH}$ for $24 \mathrm{~h}$. The mixture was suction filtered to obtain sodium silicate to be used as the silica source. The recovered residue $(\mathrm{RH}-\mathrm{NaOH})$ was washed with distilled water and dried in an oven at $383 \mathrm{~K}$ and the mass of $\mathrm{RH}-\mathrm{NaOH}$ weighed. The difference in the mass between $\mathrm{RH}-\mathrm{HNO}_{3}$ and $\mathrm{RH}-\mathrm{NaOH}$ was assumed to be equivalent to the mass of silica extracted.

\subsection{Preparation of $\mathrm{RH}-10 \mathrm{~V}$ catalyst}

The resulting sodium silicate was titrated slowly (ca. 1.0 $\mathrm{ml} / \mathrm{min}$ ) to $\mathrm{pH}=9$ with $150 \mathrm{ml}$ of $3.0 \mathrm{~mol} / \mathrm{L} \mathrm{HNO}_{3}$ containing $2.03 \mathrm{~g}$ of $\mathrm{NaVO}_{3} \cdot \mathrm{H}_{2} \mathrm{O}$ to get $10 \mathrm{wt} \%$ of vanadium in the catalyst. A brown gel was obtained and aged for $48 \mathrm{~h}$. The gel was suction filtered, washed thoroughly with distilled water, and followed by hot water several times in order to remove $\mathrm{Na}^{+}$, and oven dried at $383 \mathrm{~K}$ for $24 \mathrm{~h}$. The powder was allowed to cool in a desiccator and ground into fine powder and the sample denoted as RH-10V was kept for further use.

\subsection{Catalyst characterization}

RH-10V was characterized by FTIR spectroscopy (Perkin Elmer System 2000), $\mathrm{N}_{2}$ adsorption-desorption analysis (Micromeritics Instrument Corporation model ASAP 2000, Norcross), transmission electron microscopy (TEM, Phillips CM12), energy dispersion spectroscopy (EDS, Edax Falcon System) and DR/UV-Vis analysis (Lambda 35, Perkin Elmer).

\subsection{Catalytic activity}

As a common practice, prior to the reaction, $\mathrm{RH}-10 \mathrm{~V}$ (50 $\mathrm{mg}$ ) was activated for $24 \mathrm{~h}$ in an oven at $383 \mathrm{~K}$. The catalyst was removed from the oven and cooled in a desiccator prior to use in the catalysis. The round-bottom flask equipped with a condenser was set up in a temperature control oil bath at $343 \mathrm{~K}$. Acetophenone $(2.40 \mathrm{~g})$ in $10 \mathrm{ml}$ of acetonitrile was placed into the flask. $\mathrm{H}_{2} \mathrm{O}_{2}(4.53 \mathrm{~g}, 30 \%)$ was added drop wise into the reaction vessel within $5 \mathrm{~min}$. The reaction was allowed to run for $3 \mathrm{~h}$. During the reaction, 0.5 $\mathrm{ml}$ of the sample was withdrawn and filtered, then $10 \mu \mathrm{l}$ of cyclohexane was added as internal standard and analyzed by gas chromatography (Perkin Elmer Clarus 500) equipped with Elite Wax (30 m $\times 0.2 \mathrm{~mm}$ ID) and further confirmed by GCMS (Perkin Elmer, Clarus 600) analysis. The following are the GC and GCMS condition used: initial oven temperature $=383 \mathrm{~K}$, final oven temperature $=503 \mathrm{~K}$, ramp $1=$
$20 \mathrm{~K} / \min$ to $403 \mathrm{~K}$, ramp $2=10 \mathrm{~K} / \mathrm{min}$ to $503 \mathrm{~K}$, total run time $=11 \mathrm{~min}$.

\section{Results and discussion}

\subsection{Characterization of catalyst}

The infrared spectra of $\mathrm{RH}-10 \mathrm{~V}$ before and after reaction are illustrated in Fig. 1. As shown in Fig. 1(1), the band at $3462 \mathrm{~cm}^{-1}$ was either due to the $\mathrm{O}-\mathrm{H}$ stretching vibration of the silanol or adsorbed water molecules on the silica surface. The band at $1639 \mathrm{~cm}^{-1}$ was due to the bending vibration of the water molecules. The strong band at $1096 \mathrm{~cm}^{-1}$ corresponded to the asymmetric vibration of the siloxane bond $\mathrm{Si}-\mathrm{O}-\mathrm{Si}$, and the band at $805 \mathrm{~cm}^{-1}$ was assigned to the bending vibration of $\mathrm{Si}-\mathrm{O}-\mathrm{Si}$ bond. The transmission band observed at $472 \mathrm{~cm}^{-1}$ was due to the stretching vibration of the $\mathrm{Si}-\mathrm{O}-\mathrm{Si}$ bond. The presence of a band at $974 \mathrm{~cm}^{-1}$ indicated the $\mathrm{Si}-\mathrm{OH}$ stretching vibration in the parent silica reported in our previous study [15]. When $\mathrm{H}$ was exchanged with metal, in this case vanadium, an obvious shift of this band could be observed. Therefore, in RH-10V, the observed Si-OV vibration was shifted to $974 \mathrm{~cm}^{-1}$ due to the exchange of the $\mathrm{H}$ with $\mathrm{V}$. Thus, it was possible to conclude that the band at $974 \mathrm{~cm}^{-1}$ in the vanadium containing catalyst was due to the presence of $\mathrm{Si}-\mathrm{OV}$ bonds [14]. Moreover, the shoulder at $\sim 1024 \mathrm{~cm}^{-1}$ was assigned to the $\mathrm{V}=\mathrm{O}$ stretching vibration as reported by Gomez et al. [16] for vanadia- zirconia catalyst.

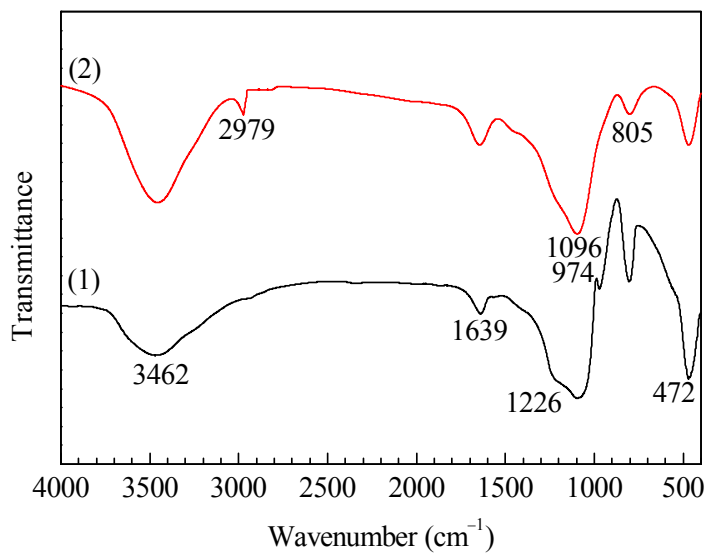

Fig. 1. FT-IR spectra of RH-10V before (1) and after (2) the reaction.

The $\mathrm{N}_{2}$ adsorption-desorption isotherms of RH-10V (Fig. 2) shows type IV isotherms and H1 hysteresis loops. H1 hysteresis loop is a characteristic of mesoporous material consisting of agglomerates or spherical particles having a relatively uniform pore size [16]. The specific surface area of RH-10V was found to be $276 \mathrm{~m}^{2} / \mathrm{g}$, and the pore volume was $0.83 \mathrm{ml} / \mathrm{g}$. The catalyst showed a narrow pore size dis- 


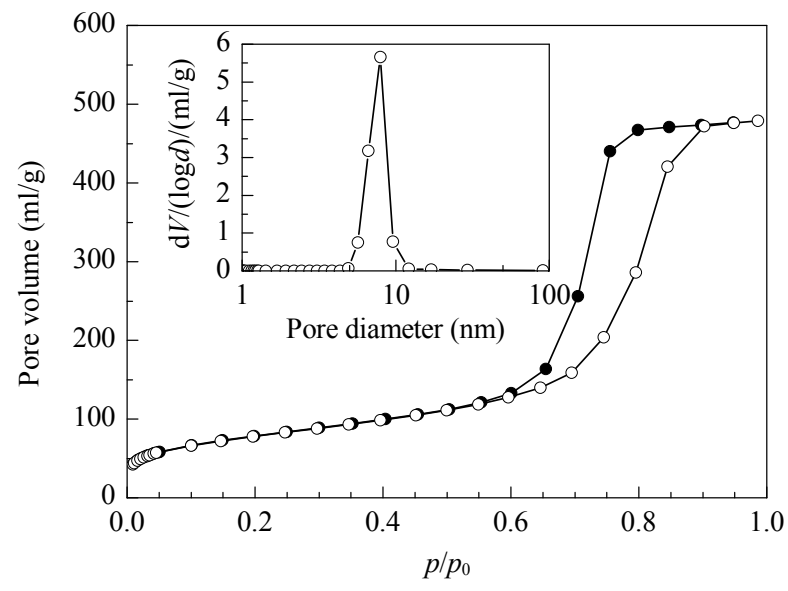

Fig. 2. The $\mathrm{N}_{2}$ adsorption-desorption isotherms and narrow pore size distribution (inset) of RH-10V.

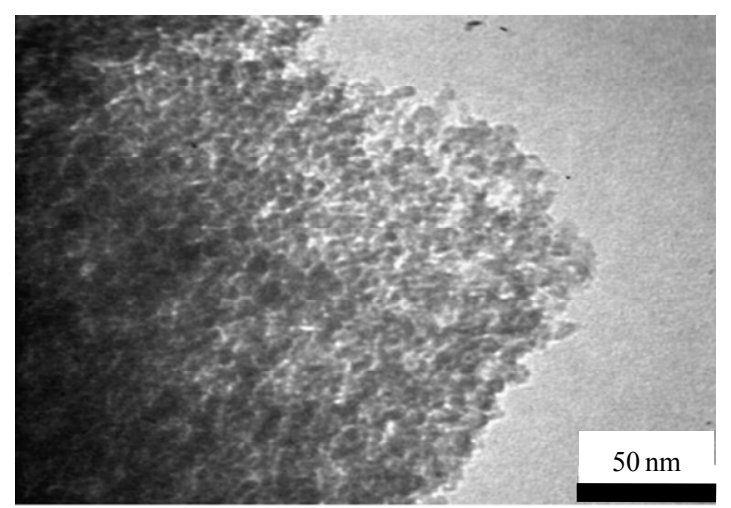

Fig. 3. TEM image of RH-10V catalyst showing the distribution of particle sizes.

tribution in the range of 5-8 $\mathrm{nm}$ which is in accordance with the characteristics of $\mathrm{H} 1$ hysteresis loop.

The TEM image of RH-10V is shown in Fig. 3. The incorporation of $\mathrm{V}$ resulted in smaller particles. The elemental composition of RH-10V was determined by EDX analysis as represented in Table 1 which confirmed the presence of carbon, oxygen, silicon, and vanadium. Si and $\mathrm{O}$ were detected due to the formation of siloxane bond $(\mathrm{Si}-\mathrm{O}-\mathrm{Si})$ and silanol group $(\mathrm{Si}-\mathrm{OH})$. These $\mathrm{Si}$ and $\mathrm{O}$ could form a $\mathrm{Si}-\mathrm{O}-\mathrm{V}$ bond, whereas the presence of small amount of carbon might arise from rice husk.

The DR/UV-Vis spectrum of the vanadium containing catalyst (Fig. 4) showed a strong band centered at $278 \mathrm{~nm}$.
Table 1 The elemental composition of RH-10V

\begin{tabular}{cc}
\hline Element & Average weight (\%) \\
\hline $\mathrm{C}$ & 2.1 \\
$\mathrm{O}$ & 69.1 \\
$\mathrm{Si}$ & 23.4 \\
$\mathrm{~V}$ & 5.4 \\
Total & 100.0 \\
\hline
\end{tabular}

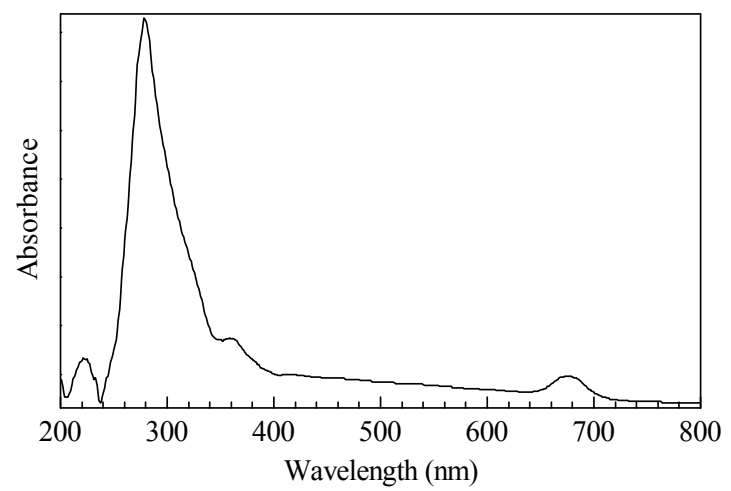

Fig. 4. The DR/UV-Vis spectrum of RH-10V.

This band could be assigned as $\mathrm{V}^{5+}$ in tetrahedral coordination [17]. The band around $330-500 \mathrm{~nm}$ region was due to the octahedral coordinated $\mathrm{V}^{5+}$ [18]. In this case, the $d-d$ transitions were also observed between 650 and $700 \mathrm{~nm}$ [17]. Thus, it could be concluded that vanadium was present solely as $\mathrm{V}^{5+}$ in the framework of silica.

\subsection{Catalyst evaluation}

The prepared catalyst was tested in the liquid phase oxidation of acetophenone. Table 2 shows the acetophenone conversion with respect to the mass of the catalyst at $343 \mathrm{~K}$. The acetophenone conversion was found to increase sharply from $11.4 \%$ to $36.3 \%$ when the catalyst mass used was increased from 30 to $50 \mathrm{mg}$. However, further increase in the catalyst mass to $100 \mathrm{mg}$ resulted in a decrease in acetophenone conversion to $12.6 \%$. This was due to the rapid decomposition of $\mathrm{H}_{2} \mathrm{O}_{2}$ over the large surface area available with a higher amount of catalyst [19]. At a higher dose of catalyst, the availability of more active sites resulted in rapid decomposition of $\mathrm{H}_{2} \mathrm{O}_{2}$, leading to lower yields. As a result, 2-hydroxyacetophenone was observed as a

Table 2 Oxidation of acetophenone using different amounts of catalyst

\begin{tabular}{|c|c|c|c|c|c|}
\hline \multirow{2}{*}{$\begin{array}{l}\text { Catalyst mass } \\
\text { (mg) }\end{array}$} & \multirow{2}{*}{$\begin{array}{l}\text { Acetophenone } \\
\text { conversion }(\%)\end{array}$} & \multicolumn{4}{|c|}{ Selectivity (\%) } \\
\hline & & Acetic acid & 2-Hydroxyacetophenone & Benzoic acid & 3-Hydroxyacetophenone \\
\hline 30 & 11.4 & 21.1 & 50.4 & 28.5 & - \\
\hline 50 & 36.3 & 20.4 & 49.1 & 19.9 & 10.6 \\
\hline 70 & 16.4 & 25.8 & 50.0 & 24.2 & - \\
\hline 100 & 12.6 & 17.3 & 62.9 & 19.8 & - \\
\hline
\end{tabular}

Reaction conditions: catalyst $=\mathrm{RH}-10 \mathrm{~V}, 343 \mathrm{~K}$, molar ratio of substrate: $\mathrm{H}_{2} \mathrm{O}_{2}=1: 2,10 \mathrm{ml} \mathrm{CH} \mathrm{CN}, 3 \mathrm{~h}$. 
by-product and decreased the selectivity of benzoic acid.

The reaction temperature was found to have a great influence on the conversion of the reaction. Thus, in the oxidation of acetophenone, the effect of temperature on the reaction was studied in the range of 303-353 $\mathrm{K}$ (Table 3). With an increase in the reaction temperature from 303 to $343 \mathrm{~K}$, there was a significant increase in the conversion from $24.3 \%$ to $36.3 \%$. Raising the reaction temperature higher to $353 \mathrm{~K}$ resulted in a slight increase of the conversion to $39.2 \%$. This was due to the rapid decomposition of $\mathrm{H}_{2} \mathrm{O}_{2}$ at $353 \mathrm{~K}$ [12]. Moreover, the selectivity toward 2-acetophenone increased with increasing temperature, this might be due to the formation of water from $\mathrm{H}_{2} \mathrm{O}_{2}$ to hydrolyze acetophenone. However, decomposition of $\mathrm{H}_{2} \mathrm{O}_{2}$ caused lack of oxidant to convert acetophenone into benzoic acid and acetic acid. Even though there was increase in conversion with temperature, the optimum reaction temperature was set at $343 \mathrm{~K}$, because at high temperatures, there are moderate conversion and rapid decomposition of $\mathrm{H}_{2} \mathrm{O}_{2}$.

The effect of $\mathrm{H}_{2} \mathrm{O}_{2}$ was studied by varying acetophenone: $\mathrm{H}_{2} \mathrm{O}_{2}$ molar ratio from 1:1 to $1: 3$ (Table 4). The conversion were $4.1 \%$ and $36.3 \%$ for $1: 1$ and $1: 2$ molar ratios, respectively. However, at a molar ratio of 1:3, the acetophenone conversion decreased. Generally, the decomposition of $\mathrm{H}_{2} \mathrm{O}_{2}$ produced water as the by-product. The water might poison the catalyst by adsorbing strongly to the vanadium centre and thus inhibiting the reaction [18]. Furthermore, decomposition of $\mathrm{H}_{2} \mathrm{O}_{2}$ (oxidant) reduced the formation of acetic acid and benzoic acid, while the hydroxylation product, 2 -acetophenone was easily formed in the presence of water. It was thus concluded that the optimum molar ratio was 1:2.

From the data in Tables 3 and 4, phenol was only detected at $353 \mathrm{~K}$ when the acetophenone: $\mathrm{H}_{2} \mathrm{O}_{2}$ molar ratio was 1:3. The formation of phenol must originate from the

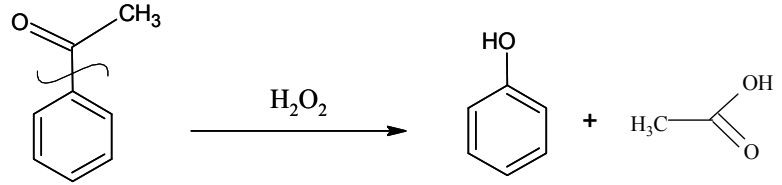

Scheme 1. The formation of phenol.

breaking of the bond as shown in Scheme 1. While acetic acid was detected under all the experimental conditions studied, it was not clear why phenol was only detected under certain conditions as noted above. It was concluded that this anomaly required further investigation.

After optimization of the reaction conditions it resulted in $36.28 \%$ conversion of acetophenone yielding $20.4 \%$ acetic acid, $19.8 \%$ benzoic acid, 49.2\% 2-hydroxyacetophenone, and $10.6 \% 3$-hydroxyacetophenone. In previous studies, 1,3-dinitrobenzene [2] had been used as the solvent for this reaction and by adding $t$-BuOK, a conversion of $91.7 \%$ acetophenone and $58.2 \%$ yield of benzoic acid were achieved. However, the utilization of $t$ - $\mathrm{BuOK}$ as an additive is expensive for the industrial production of benzoic acid and secondly, the homogeneous system creates problem for separation. Some researchers [3,5] used acid catalyst in a two-step oxidation of acetophenone by forming $\alpha$-nitroso-acetophenone as the intermediate. However, the intermediate formed is unstable in acidic condition and isomerizes to form benzoylformaldehyde oxime as a by-product. Hence, the two-step oxidation of acetophenone is not practical in the industry due to the difficulty in isolating the products and the lengthy time involved. Chumbahale et al. [4] used vapor phase oxidation of acetophenone over a long contact time $(58.5 \mathrm{~h})$ to obtain a high conversion (74.8\%) and high selectivity (96.9\%) towards benzoic acid. However, this method yielded side-products such as maleic anhydride, benzyl alcohol, benzaldehyde, phathalic anhy-

Table 3 The oxidation of acetophenone as a function of temperature

\begin{tabular}{ccccccc}
\hline Temperature & Conversion & \multicolumn{3}{c}{ Selectivity (\%) } \\
\cline { 3 - 6 }$(\mathrm{K})$ & $(\%)$ & Acetic acid & 2-Hydroxyacetophenone & Benzoic acid & 3-Hydroxyacetophenone & Ph \\
\hline 303 & 24.3 & 26.5 & 48.2 & 25.3 & - \\
323 & 30.4 & 22.8 & 44.6 & 20.2 & 12.4 \\
343 & 36.3 & 20.4 & 49.2 & 19.8 & - \\
353 & 39.2 & 14.5 & 58.2 & 10.3 & - \\
\hline
\end{tabular}

Reaction conditions: $50 \mathrm{mg}$ RH-10V, molar ratio of substrate: $\mathrm{H}_{2} \mathrm{O}_{2}=1: 2,10 \mathrm{ml} \mathrm{CH} \mathrm{CN}$ Solvent, $3 \mathrm{~h}$.

Table 4 The oxidation of acetophenone using different acetophenone: $\mathrm{H}_{2} \mathrm{O}_{2}$ molar ratios

\begin{tabular}{|c|c|c|c|c|c|c|}
\hline \multirow{2}{*}{$\begin{array}{c}\text { Acetophenone: } \mathrm{H}_{2} \mathrm{O}_{2} \\
\text { molar ratio }\end{array}$} & \multirow{2}{*}{$\begin{array}{c}\text { Conversion } \\
(\%)\end{array}$} & \multicolumn{5}{|c|}{ Selectivity $(\%)$} \\
\hline & & Acetic acid & 2-Hydroxyacetophenone & Benzoic acid & 3-Hydroxyacetophenone & $\mathrm{Ph}$ \\
\hline $1: 1$ & 4.1 & 56.3 & 43.7 & - & - & - \\
\hline $1: 2$ & 36.3 & 20.4 & 49.2 & 19.8 & 10.6 & - \\
\hline $1: 3$ & 17.2 & 14.4 & 54.3 & 21.1 & - & 10.2 \\
\hline
\end{tabular}

Reaction conditions: $50 \mathrm{mg} \mathrm{RH}-10 \mathrm{~V}, 343 \mathrm{~K}, \mathrm{CH}_{3} \mathrm{CN}$ solvent, $3 \mathrm{~h}$. 
dride, and other unidentified products. It is quite clear that $\mathrm{RH}-10 \mathrm{~V}$ is by far a better catalyst for the oxidation of acetophenone and to break the single bond $\alpha$ to the carbonyl group.

To test the catalyst reusability, $\mathrm{RH}-10 \mathrm{~V}$ was used consecutively for 3 cycles as shown in Table 5. The used catalyst was filtered and regenerated by heating at $383 \mathrm{~K}$ for 24 h. After 3 runs, there was a decrease in conversion (17.7\%). The re-used catalyst was subjected to FT-IR analysis as depicted in Fig. 1(2). The appearance of the vibration at $2979 \mathrm{~cm}^{-1}$ in the FT-IR spectrum of the used catalyst might be due to adsorption of the organic compounds on the catalyst surface. This showed that the temperature for regeneration is not enough for removing the adsorbed organic compounds which resulted in catalyst poisoning. Hence some active sites of the catalyst had been blocked by the organic products and thereby lowering the catalytic activity. The objective of the present study did not involve any attempt to remove the organics, however, further work is in progress to remove organics adsorbed on the catalyst so that its efficiency can be improved.

Table 5 The reusability of RH-10V

\begin{tabular}{cc}
\hline Cycle & Conversion $(\%)$ \\
\hline 1 & 36.3 \\
2 & 21.5 \\
3 & 17.7 \\
\hline
\end{tabular}

Reaction conditions: $50 \mathrm{mg} \mathrm{RH}-10 \mathrm{~V}, 343 \mathrm{~K}$, molar ratio of substrate: $\mathrm{H}_{2} \mathrm{O}_{2}=1: 2,10 \mathrm{ml} \mathrm{CH} \mathrm{C}_{3} \mathrm{CN}$ solvent, $3 \mathrm{~h}$.

\section{Conclusions}

In summary, a template-free vanadium-silica catalyst was successfully synthesized from RH via a simple sol-gel and solvent extraction techniques. The catalyst was developed in a simple, cost-effective, and green procedure to investigate the liquid phase oxidation of acetophenone. RH-10V was found to be more active to break the $\mathrm{C}-\mathrm{C}$ single bond $\alpha$ to the carbonyl group compared with the catalysts published in the literature. The preparation of the catalyst does not involve calcination which reduces the demand on the energy necessary in the synthesis. This study have benefits to both academic and industry for alternative methods to break the $\mathrm{C}-\mathrm{C}$ bond linking the $\alpha$-carbon connected to the carbonyl carbon in ketones. Further studies are in progress in our group to improve the reusability of $\mathrm{RH}-10 \mathrm{~V}$ by removing the organics adsorbed on the catalyst.

\section{References}

1 Perkin R. JChem Educ, 1984, 61: 551

2 Bjorsvik H R, Liguori L, Gonzalez R R, Merinero J A V. Tetrahdron Lett, 2002, 43: 4985

3 Tezuka H, Kato M, Sonehara Y. J Chem Soc, Perkin Trans II, 1985: 1643

4 Chumbahale V R, Paradhy S A, Anilkumar M, Kadam S T, Bokade V V. Chem Eng Res Design, 2005, 83: 75

5 Marziano N C, Ronchin L, Tortato C, Ronchin S, Vavasori A. J Mol Catal A, 2005, 235: 26

6 Downard C D, Roberts L J, Morrow J D. Clin Pharmacol Ther, 1995, 57: 441

7 van Schle P M, Young L Y. Bioremediation J, 2000, 4: 1

8 Wade L G. Organic Chemistry. 6th Ed. United States of America: Pearson Education International, 2006. 852

9 Du G, Lim S, Pinault M, Wang C, Fang F, Pfefferle L, Haller G L. J Catal, 2008, 253: 74

10 Trakranpurk W, Hoonsart P. Chin J Catal, 2007, 28: 290

11 Shul'pin G B, Mishra G S, Shul'pin L S, Strelkova T V, Pombeiro A J L. Catal Commun, 2007, 8: 1516

12 Adam F, Andas J, Rahman I A. Chem Eng J, 2010, 165: 658

13 Adam F, Chew T S. Open Colloid Sci J, 2012, 5:1

14 Wang W J, Lin H Y, Chen Y M. J Porous Mater, 2007, 14: 137

15 Adam F, Chew T S, Andas J. J Sol-Gel Sci Technol, 2011, 59: 580

16 Gomez Bernal H, Caero L C, Finocchio E, Busca G. Appl Catal A, 2009, 369: 27

17 Gontier S, Tuel A. Microporous Mater, 1995, 5: 161

18 Neumann R, Elad M L. Appl Catal A, 1995, 122: 85

19 Singh A P, Selvam T. Appl Catal A, 1996, 143: 111 